\title{
Detection of Hepatitis E Virus in Sewage After an Outbreak on a French Island
}

\author{
Miura Takayuki ${ }^{1,6}$, Lhomme Sébastien ${ }^{2}$, Le Saux Jean-Claude ${ }^{1}$, Le Mehaute Philippe ${ }^{3}$, Guillois \\ Yvonnick ${ }^{4}$, Couturier Elizabeth ${ }^{5}$, Izopet Jacques ${ }^{2}$, Abranavel Florence ${ }^{2}$, Le Guyader Soizick ${ }^{1,{ }^{*}}$
}

${ }^{1}$ Laboratoire de Microbiologie, LSEM-SG2M, IFREMER, BP 21105, 44311, Nantes Cedex 03, France

${ }^{2}$ New Industry Creation Hatchery Center (NICHe), Tohoku University, 6-6-04 Aoba, Aramaki, Aoba-Ku, Sendai, 980-8579, Japan

${ }^{3}$ National Reference Center for HEV, Centre Hospitalier Universitaire, Toulouse, France

${ }^{4}$ SAUR, Direction générale Ouest, Vannes, France

${ }^{5}$ Regional Epidemiology Unit for the Brittany region, Institut de veille sanitaire, Rennes, France

${ }^{6}$ Department of Infectious Diseases, Institut de Veille Sanitaire, Saint-Maurice, France

*Corresponding author : Soizick Le Guyader, email address : sleguyad@ifremer.fr

\begin{abstract}
:
A hepatitis $E$ outbreak, which occurred on a small isolated island, provided an opportunity to evaluate the association between the number of hepatitis $\mathrm{E}$ cases in the community and the concentration of virus detected in sewage. Samples were collected from the different sewage treatment plants from the island and analyzed for the presence of hepatitis E (HEV) virus using real-time RT-PCR. We demonstrated that if 1-4 \% of inhabitants connected to a WWTP were infected with HEV, raw sewage contained HEV at detectable levels. The finding that such a small number of infected people can contaminate municipal sewage works raises the potential of the further distribution of the virus. Indeed, investigating the routes of transmission of $\mathrm{HEV}$, including the potential for sewage effluent to contain infectious HEV, may help us to better understand the epidemiology of this pathogen, which is considered to be an emerging concern in Europe
\end{abstract}

Keywords : Hepatitis E virus, Wastewater treatment plant, Quantification 


\section{Introduction}

The demand for clean water for both drinking and food production is increasing, largely due to the increase in the global population. Contaminated water poses a significant risk to public health, as evidenced by the growing recognition of waterborne disease outbreaks (Gall et al. 2015; Uyttendaele et al. 2015). Nowadays the transmission of human enteric viruses via contaminated water and foods is an important issue due to gastroenteritis and hepatitis outbreaks, which occur worldwide (Gibson 2014; Koopmans 2013). Inadequate sanitation conditions and ineffective sewage treatment procedures favor virus transmission, as first demonstrated in the late 1940s, when poliovirus was detected in sewage (Metcalf et al. 1995). Human enteric viruses, comprising a variety of virus families, are shed in high concentrations in human feces. Being highly resistant to sewage treatment, once discharged from treatment plants they may contaminate environmental waters (Gibson 2014; La Rosa et al. 2010; Lodder et al. 2005; Myrmel et al. 2015; Sano et al. 2011). Up to now, limited-data are available for some viruses such as hepatitis E virus (HEV), which is considered to be an emerging concern in Europe (Abranavel et al. 2013; La Rosa et al. 2010; Smith et al. 2016; van der Poel 2014).

HEV is the sole member of the genus Orthohepevirus, which is in the family Hepeviridae. It is a small non-enveloped virus with a positive-sense, single-stranded RNA genome, and four major genotypes (Abranavel et al. 2013). The transmission is primarily via the fecal-oral route; however, consumption of undercooked meat products has been linked to clinical cases, and the zoonotic potential of genotypes 3 and 4 (infecting diverse animals) has been demonstrated (Pavio et al. 2015). In France, like in most European countries, genotype $3 \mathrm{HEV}$ is predominant and has been reported to be circulating among the French population (Abranavel et al. 2012; Lhomme et al. 2015).

Following an outbreak of hepatitis E disease, which occurred in a contained environment (Guillois et al. 2016), we considered that it represented a unique opportunity to estimate the number of infected individuals that are needed for HEV to be present and detectable in sewage. To our knowledge, studies investigating the relationship between the number of infected people and viral concentrations in sewage have not yet been reported.

\section{Materials and Methods}

Outbreak Description

Following a wedding event involving the consumption of undercooked pork on the 28th of September 2013, three clinical cases of hepatitis E were identified on an island in western France (Guillois et al. 2016). After an epidemiological investigation and serological tests, an additional 14 individuals were also considered to be potential HEV excretors, due to the presence of IgM in serum samples. Indeed, the persistence of HEV in stool samples after the clearance of $\operatorname{IgM}$ in blood serum has been reported (Kamar et al. 2014). 
Island Description

The island, located off the western coast of France, has an area of $85.6 \mathrm{~km}^{2}$ and a population of 5158 inhabitants (density of 60.2 inhabitants $/ \mathrm{km}^{2}$ ) (INSEE, January 2013). The island has a total of 6242 dwellings, 2455 of these are primary dwellings, the others are holiday homes, which are only used during the summer months. In 2010, 53 farms were identified, with 800 cattle, 2235 sheep, and some horticultural activities (vegetables), but no commercially farmed pigs were present on the island (French agriculture ministry data). The main activity on the island is tourism, which occurs primarily over summer, from May to the end of September.

Wastewater Treatment Plants (WWTPs) and Sample Collection

Approximately half of the dwellings on the island have septic tanks, and the other half are connected to four WWTPs. Three WWTPs (A, B, C) have simple treatment processes with lagoons (three serial ponds that are gravity fed), whereas the largest WWTP (D) uses activated sludge treatment. All four WWTPs treat small volumes of domestic wastewater $\left(30,24,97\right.$, and $1486 \mathrm{~m}^{3}$ per day for WWTP A, B, C, and D, respectively) (Pers. Comm. AIC Conseil, 2012). Grab samples of less than $5 \mathrm{~L}$ of influent were collected on the 19th of December 2013, on the 8, 20, and 27th of January 2014, and on the 29th of March 2014. Grab effluent samples were collected at the same dates, except December 19th. For technical reasons, no samples were collected from WWTP A and D on January 27 (neither influent or effluent). The samples were transported by boat and car to the laboratory within $24 \mathrm{~h}$ of collection and were immediately processed or frozen at $-20^{\circ} \mathrm{C}$.

\section{Viral RNA Extraction}

Effluent samples were concentrated from $1 \mathrm{~L}$ to $40 \mathrm{~mL}$ using cross-flow ultrafiltration (Vivaflow 50; Sartorius, Germany) (Sima et al. 2011). The $40 \mathrm{~mL}$ effluent concentrates, as well as $40 \mathrm{~mL}$ sub-samples of influent (with no concentration), were spiked with $10^{6}$ genome copies of mengovirus strain vMC0 (kindly provided by A. Bosch, University of Barcelona, Spain), mixed with polyethylene glycol 6000 (PEG) (Sigma-Aldrich, St Quentin, France) and rocked overnight at $4{ }^{\circ} \mathrm{C}$ (Sima et al. 2011). After centrifugation for $1.5 \mathrm{~h}$ at $13,500 \times \mathrm{g}$, supernatants were discarded and the PEG pellet was collected for nucleic acid extraction. Viral RNA was extracted using a NucliSENS kit (bioMérieux, Lyon, France) according to the manufacturer's instructions, with minor modifications (Sima et al. 2011).

\section{Quantitative Detection}

Amplification for the Mengovirus and HEV was carried out using the Ultrasens QRT-PCR kit (Invitrogen, France) using previously published cycling conditions, primers, and probes (Grodzki et 
al. 2014; Jothikumar et al. 2006). The extraction efficiency of the spiked mengovirus was expressed as a percentage for each sample (Sima et al. 2011).

Only samples with an extraction efficiency above $1 \%$ were considered valid and suitable for quantification. After verification of the absence of inhibition (based on serial dilutions of nucleic acids), the number of RNA copies (RNAc) was estimated based on a standard curve derived from an in vitro transcription plasmid containing a fragment of the HEV genotype $3 \mathrm{f}$ strain (kindly provided by N. Pavio, Anses, Paris France) (Grodzki et al. 2014). The final concentration was then back calculated based on the volume of nucleic acid analyzed and expressed per L.

\section{Typing of Positive Samples}

HEV typing was undertaken via amplification of a fragment of open-reading frame 2 (ORF2) by nested PCR. Briefly, complementary DNA (cDNA) was obtained through a reverse transcription reaction using super script III reverse transcriptase (invitrogen), and the partial ORF2 region of HEV was amplified using AmpliTaq DNA polymerase with buffer II (Applied Biosystems, France) with primers $3156 \mathrm{~N}$ and $3157 \mathrm{~N}$ for the first PCR and $3158 \mathrm{~N}$ and $3159 \mathrm{~N}$ for the second PCR. Expected length of second PCR product was 348 bp (Cooper et al. 2005; Legrand-Abravanel et al. 2009). Amplified products were cloned and ten different clones were sequenced.

\section{Expected Concentration of HEV in Influent Samples}

Based on (1) the WWTP flow rates; (2) the estimated excretion of $200 \mathrm{~mL}$ of stool per day per individual; and (3) published data on the concentrations of HEV shed in feces (Lodder et al. 2012; Takahashi et al. 2007), we calculated the expected concentrations of HEV in wastewater assuming that the WWTPs collected all the viral particles shed by the infected individuals.

\section{Results}

\section{Quantitative Detection}

A total of 18 influent and 14 effluent samples were collected between December 19th 2013 and March 29th 2014. Mean extraction efficiencies were 10, 11, 13, and $12 \%$ (influent samples) and 8, 5, 9, and $13 \%$ (effluent samples) for WWTP A, B, C and D, respectively. Four influent samples were positive for HEV; three of these were collected from WWTP B and one from WWTP C (Table 1). In December, the HEV concentration detected in the influent sample from WWTP B was 2-logs higher than that from WWTP C. Due to the time of year (christmas), and also poor climatic conditions that made transit to the island difficult (no boat transportation), wastewater samples were only collected 3 weeks later on the 8th of January, and only the WWTP B influent sample was positive at that time. The concentration was in the same range the following week, and at the end of January, all influent 
samples were found to be under the limit of detection (2.2 $\log$ RNAc/L, Table 1). None of the effluent samples were positive for HEV.

\section{Table 1}

Hepatitis E virus concentrations detected in influent wastewater samples

\begin{tabular}{|l|l|l|l|l|l|}
\hline WWTP & Dec 19 & Jan 08 & Jan 20 & Jan 27 & Mar 29 \\
\hline A & $<$ LOD & $<$ LOD & $<$ LOD & - & $<$ LOD \\
\hline B & 5.8 & 3.0 & 3.0 & $<$ LOD & $<$ LOD \\
\hline C & 3.6 & $<$ LOD & $<$ LOD & $<$ LOD & $<$ LOD \\
\hline $\mathrm{D}$ & $<$ LOD & $<$ LOD & $<$ LOD & - & $<$ LOD \\
\hline
\end{tabular}

Concentrations are expressed in log RNAc/L, LOD: limit of detection (2.2 log RNAc/L)

- no sample collected

\section{Typing}

Partial ORF2 HEV sequences were obtained from the influent collected from WWTP B on the 19th of December 2013 and on the 20th of January 2014, and these were found to be identical to a $3 f$ strain that was obtained from the three clinical cases (Guillois et al. 2016).

\section{Geographical Investigation}

The source of the contamination was identified as the pork meat eaten during the wedding event. The WWTPs that wedding participant houses were connected to were identified, based on postal codes. Seven wedding participants lived in houses with septic tanks; three of them were infected with HEV. The other 45 participants, including 14 infected participants, lived in houses connected to three of the four WWTPs (Table 2). None of the meal participants' houses were connected to WWTP A, which can be used as a control to demonstrate absence of HEV in sewage. WWTP B, C, and D received wastewater from a comparable number of infected individuals (Table 2). Expected viral concentrations, expressed as log RNA copies per liter of influent, were calculated based on the volume of sewage entering each plant (data provided by the operator), and the number of viruses potentially excreted by infected people connected to the WWTP. This gave low concentrations, close to the limit of detection of the HEV method. These estimations aligned well with the concentrations detected in samples from the WWTPs, as HEV was never detected in WWTP A, and the predicted and actual concentration ranges for WWTP B and C were similar (Table 2). We expected to detect some HEV in samples from WWTP D based on the maximum concentration calculated; however, our results fit within the expected range, especially considering that we only had access to grab samples 
that were potentially not representative of the average HEV concentration in the influent.

Table 2

HEV influent concentrations calculated based on infected populations and compared to detected concentrations

\begin{tabular}{|c|c|c|c|c|c|}
\hline WWTP & $\begin{array}{l}\text { Flow } \\
\text { rate }^{\text {a }}\end{array}$ & $\begin{array}{l}\# \quad \text { of connected } \\
\text { inhabitants }\end{array}$ & $\begin{array}{l}\# \text { of infected } \\
\text { patients }\end{array}$ & $\begin{array}{l}\text { Calculated mean } \\
\text { conc. (range) }^{\text {b }}\end{array}$ & $\begin{array}{l}\text { Detected } \\
\text { concentration }^{c}\end{array}$ \\
\hline A & 30 & 147 & 0 & negative & none \\
\hline B & 24 & 117 & 5 & $1.8(0.6-5.9)$ & $3.0-5.8$ \\
\hline $\mathrm{C}$ & 97 & 474 & 4 & $1.1(-0.1-5.2)$ & 3.6 \\
\hline $\mathrm{D}$ & 1486 & 2762 & 5 & $0.02(-1.2-4.1)$ & none \\
\hline \multicolumn{6}{|c|}{ a mean value expressed in $\mathrm{m}^{3} /$ day } \\
\hline \multicolumn{6}{|c|}{$\begin{array}{l}{ }^{\mathrm{b}} \text { mean concentrations calculated based on fecal concentrations of } 3 \log \mathrm{RNAc} / \mathrm{mL} \text { (range from } 2 \text { to } \\
\log \mathrm{RNAc} / \mathrm{mL} \text { ) for HEV (Takahashi et al. 2007), and expressed in } \log \mathrm{RNAc} / \mathrm{L}\end{array}$} \\
\hline
\end{tabular}

\section{Discussion}

This study shows that when as little as $1-4 \%$ of inhabitants connected to a small WWTP (receiving less than hundred $\mathrm{m}^{3} /$ day of raw sewage) were infected with $\mathrm{HEV}$, raw sewage contained $\mathrm{HEV}$ at detectable levels up to 3 months after the contamination event. In the larger WWTP (receiving more than a thousand $\mathrm{m}^{3} /$ day of raw sewage), the five infected people represented only $0.2 \%$ of the connected inhabitants and the virus was not detected. The entire population of the island was not tested for HEV, but finding one WWTP negative (or at least under the limit of detection of the method) suggests that HEV is not circulating all the time. Obtaining sewage samples that are representative of the viral load in the WWTP is challenging as it requires either large volumes or 24-H composite samples. Samples of large volume are difficult to handle, especially if on site concentration is not possible, and concentration steps can lead to an increase in inhibitory substances, which impede the enzymes used in the molecular assays (either the reverse transcriptase or the polymerase). However, to reduce the potential for false-negative results, inhibition of molecular assays may be overcome by incorporating quality control measures, such as the use of an external virus to determine extraction efficiency, and nucleic acid dilution (Myrmel et al. 2015; Ruggeri et al. 2015; Sima et al. 2011).

The detected concentrations of HEV were close to the highest calculated (predicted) 
concentrations. This suggests that HEV shedding was at least as estimated and confirmed that patients were still excreting viruses a few weeks after the infection event. Indeed, the collection of the first sewage samples was delayed in relation to the onset of disease in patients, and due to poor weather conditions sampling was not undertaken during February. The WWTPs applied basic treatment regimes and the removal efficiency explain the absence of HEV in treated sewage, as even a reduction of 1-2 logs would result in concentrations below the limit of detection of the test method. This suggests that we need to increase the sensitivity of the detection method, and further investigation into the potential presence of infectious HEV in sewage effluent in larger communities should be undertaken.

Human to human transmission of hepatitis $\mathrm{E}$ is rare, and the food or water transmission route are more frequently involved (Yugo et al. 2013). Regarding zoonotic strains such as genotype 3, the consumption of undercooked meat is suggested to be the primary route (Pavio et al. 2015). However, the high prevalence of this genotype in the human population in Europe, but also worldwide, may raise the question of other routes of transmission. This genotype is the most frequently detected in sewage in many countries (La Rosa et al. 2010; Masclaux et al. 2013; Smith et al. 2016). Considering that inadequately treated sewage is a major factor in the transmission of human enteric viruses (EFSA 2011), one of the first questions raised is 'how many infected people are needed to allow the detection of virus in raw sewage?' This question is difficult to research, as WWTPs usually collect sewage from a large number of people, for whom the infection status is not always known (i.e., un-diagnosed cases) and outbreaks often involve people living in disparate places that are connected to different WWTPs. Others factors such as industrial wastewater may also contribute to viral particle dilution. Fortunately, this outbreak took place on an island, at a time when tourism activity was low and the population was relatively static, giving us the opportunity to evaluate the relationship between the number of infected people and the viral concentration in raw sewage.

Elements that favor adaptation of zoonotic strains (such as HEV genotype 3) to humans, potentially leading to an increase in human to human transmission, are not clear. The environment may play a role and sharing information on clinical cases with WWTP operators may help to prevent further distribution of the virus in the environment and downstream contamination. We demonstrated that if $1 \%$ of inhabitants connected to a WWTP were infected with HEV, sewage influent contained $\mathrm{HEV}$ at detectable levels. Viral detection in wastewater is not being conducted on a routine basis yet, but it is feasible considering recent method development efforts, kit availability, and the sensitivity of amplification methods, which target a variety of different viruses. Although screening all viral pathogens requires expensive equipment, such as the microfluidic or next generation sequencing approaches (Bibby et al. 2013; Ishii et al. 2014; Newton et al. 2015), searching for some specific viruses of public health concern in sewage may be feasible in developed countries. The impact of one 
hepatitis A shedder on shellfish contamination was just demonstrated, leading to clinical cases in consumers (Boxman et al. 2016). In the era of rapid networking via the internet, we believe that enhanced data sharing with respect to geographical locations of diagnosed cases will help to prevent further transmission through avoiding subsequent water and food contamination.

\section{Acknowledgments}

This study was supported by the Japan Society for the Promotion of Science (JSPS) through JSPS Research Fellowships for Young Scientists (23-4434) (TM), by Grant 2010 CESA 01003 'Hevecodyn' from the Agence Nationale pour la recherche (ANR), and by the EU-H2020 Grant $\mathrm{N}^{\circ} 643476$ Compare. We acknowledge the help of the SAUR technicians for sampling. We are grateful to Catherine McLeod (Seafood Safety Assessment) for a critical review of the manuscript.

Compliance with Ethical Standards

Conflict of interest

All the authors have no conflict of interest.

\section{References}

Abranavel, F., Lhomme, S., Dubois, M., Peron, J.-M., Alric, L., Rostaing, L., et al. (2013). Hepatitis E virus. Medecine et Maladies Infectieuses, 43, 263-270.

Abranavel, F., Sandres-Saune, K., Lhomme, S., Dubois, M., Mansuy, J.-M., \& Izopet, J. (2012). Genotype 3 diversity and quantification of hepatitis E virus RNA. J Clin Microbiol, 50, 897-902. Bibby, K., \& Peccia, J. (2013). Identification of viral pathogen diversity in sewage sludge by metagenome analysis. Environ Sci Technol, 47, 1945-1951.

Boxman, I., Verhoef, L., Vennema, H., Ngui, S., Friesema, I. H., Whiteside, C., et al. (2016). International linkage of two food-borne hepatitis A clusters through traceback of mussels, the Netherlands, 2012. Euro Surveill,. doi:10.2807/1560-7917.ES.2016.21.3.30113.

Cooper, K., Huang, F. F., Batista, L., Rayo, C. D., Beznilla, J. C., Toth, T. E., \& Meng, X. J. (2005). Identification of genotype 3 hepatitis $\mathrm{E}$ virus (HEV) in serum and fecal samples from pigs in Thailand and Mexico, where genotype 1 and 2 HEV strains are prevalent in the respective human populations. J Clin Microbiol, 43, 1684-1688.

EFSA. (2011). Scientifc opinion on an update on the present knowledge on the occurence and control of foodborne viruses. EFSA J, 9, 1-96.

Gall, A., Marinas, B. J., Lu, Y., \& Shisler, J. L. (2015). Waterborne viruses: a barrier to safe drinking water. PLoS Pathog, 11, e1004867.

Gibson, K. E. (2014). Viral pathogen in water: occurence, public health impact, and available control 
strategies. Curr Opin Virol, 4, 50-57.

Grodzki, M., Schaeffer, J., Piquet, J.-C., Le Saux, J.-C., Chevé, J., Ollivier, J., et al. (2014). Bioaccumulation efficiency, tissue distribution, and environmental occurrence of hepatitis $\mathrm{E}$ virus in bivalve shellfish from France. Appl Environ Microbiol, 80, 4269-4276.

Guillois, Y., Abranavel, F., Miura, T., Pavio, N., Vaillant, V., Lhomme, S., et al. (2016). High proportion of asymptomatic infections in an outbreak of hepatitis $E$ associated with a spit-roasted piglet, France, 2013. Clin Infect Dis, 62, 351-357.

Ishii, S., Kitamura, G., Segawa, T., Kobayashi, A., Miura, T., \& Okabe, S. (2014). Microfluidic quantitative PCR for simulteneous quantification of multiple viruses in environmental water samples. Appl Environ Microbiol, 80, 7505-7511.

Jothikumar, N., Cromeans, T. L., Roberstib, B. H., Meng, X. J., \& Hill, V. R. (2006). A broadly reactive one-step real-time RT-PCR assay for rapid and sensitive detection of hepatitis E virus. J Virol Methods, 131, 65-71.

Kamar, N., Dalton, H. R., Abranavel, F., \& Izopet, J. (2014). Hepatitis E virus infection. Clin Microbiol Rev, 27, 116-138.

Koopmans, M. (2013). Surveillance strategy for early detection of unusual infectious disease events. Curr Opin Virol, 3, 185-191.

La Rosa, G., Pourshaban, M., Iaconelli, M., Vennarucci, V. S., \& Muscillo, M. (2010). Molecular detection of hepatitis E virus in sewage samples. Appl Environ Microbiol, 76, 5870-5873.

Legrand-Abravanel, F., Mansuy, J.-M., Dubois, M., Kamar, N., Peron, J.-M., Rostaing, L., \& Izopet, J. (2009). Hepatitis E virus genotype 3 diversity, France. Emerg Infect Dis, 15, 110-114.

Lhomme, S., Abranavel, F., Dubois, M., Chapuy-Regaud, S., Sandres-Saune, K., Mansuy, J.-M., et al. (2015). Temporal evolution of the distribution of hepatitis E virus genotypes in Southwestern France. Infect Genet Evol, 35, 50-55.

Lodder, W. J., Buisman, A. M., Rutjes, S. A., Heijne, J. C., Teunis, P. F., \& de Roda Husman, A. M. (2012). Feasability of quantitative environmental surveillance in poliovirus eradication strategies. Appl Environ Microbiol, 78, 3800-3805.

Lodder, W. J., \& de Roda Husman, A. M. (2005). Presence of noroviruses and other enteric viruses in sewage and surface waters in the Netherlands. Appl Environ Microbiol, 71, 1453-1461.

Masclaux, F. G., Hotz, P., Friedli, D., Savova-Bianchi, D., \& Oppliger, A. (2013). High occurence of hepatitis E virus in samples from wastewater treatment plants in Switzerland and comparison with other enteric viruses. Water Res, 47, 5101-5109.

Metcalf, T., Melnick, J. L., \& Estes, M. K. (1995). Environmental Microbiology: from detection of virus in sewage and water by isolation to identification by molecular biology- a trip of over 50 years. Ann Rev Microbiol, 49, 461-487. 
Myrmel, M., Lange, H., \& Rimstad, E. (2015). A 1-year quantitiative survey of noro-, adeno-, human boca-, and hepatitis E viruses in raw and secondarily treated sewage from two plants in Norway. Food Environ Virol, 7, 213-223.

Newton, R., McLellan, S. L., Dila, D. K., Vineis, J. H., Morrison, H. G., Eren, A. M., \& Sogin, M. L. (2015). Sewage reflects the microbiomes of human populations. mBio, 6, e02574.

Pavio, N., Meng, X.-J., \& Doceul, V. (2015). Zoonotic origin of hepatitis E. Curr Opin Virol, 10, 34 41.

Ruggeri, F., Bonomo, P., Ianiro, G., Battistone, A., Delogu, R., Germinario, C., et al. (2015). Rotavirus genotypes in sewage treatment plants and in children hospitalized with acute diarrhea in Italy in 2010 and 2011. Appl Environ Microbiol, 81, 241-249.

Sano, D. U., Perez-Sautu, U., Guix, S., Pinto, R. M., Miura, T., Okabe, S., \& Bosch, A. (2011). Quantification and genotyping of human sapoviruses in the Llobregat river catchment, Spain. Appl Environ Microbiol, 77, 111-114.

Sima, L. C., Schaeffer, J., Le Saux, J.-C., Parnaudeau, S., Elimelech, M., \& Le Guyader, F. S. (2011). Calicivirus removal in a membrane bioreactor wastewater treatment plant. Appl Environ Microbiol, 77, 5170-5177.

Smith, D., Paddy, J. O., \& Simmonds, P. (2016). The use of human sewage screening for community surveillance of hepatitis E virus in the UK. J Med Virol, 88(5), 915-918. (online first doi).

Takahashi, M., Tanaka, T., Azuma, M., Kusano, E., Aikawa, T., Shibayama, T., et al. (2007). Prolonged fecal shedding of hepatitis E virus (HEV) during sporadic acute hepatitis E: evaluation of infectivity of HEV in fecal specimens in a cell culture system. J Clin Microbiol, 45, 36713679 .

Uyttendaele, M., Jaykus, L.-A., Amoah, P., Chiodini, A., Cunliffe, D., Jacxsens, L., et al. (2015). Microbial hazards in irrigation water: standards, norms, and testing to manage use of water in fresh produce primary production. Compr Rev Food Sci Food Saf, 14, 336-356.

van der Poel, W. H. M. (2014). Food and environmental routes of hepatitis E virus transmission. Curr Opin Virol, 4, 91-96.

Yugo, D. M., \& Meng, X.-J. (2013). Hepatitis E virus: foodborne, waterborne and zoonotic transmission. Int J Environ Res Public Health, 10, 4507-4533. 